I N S T I T U T O

DE

M E D I C I N A

T R O P I C A L

DE

S ÃO PAULO

JOURNAL OF THE SÃO PAULO INSTITUTE OF TROPICAL MEDICINE

${ }^{1}$ Ondokuz Mayis University, Faculty of Medicine, Department of Radiology, Samsun, Turkey

${ }^{2}$ Ondokuz Mayis University, Faculty of Medicine, Department of Infectious Disease and Clinical Microbiology, Samsun, Turkey

${ }^{3}$ Ondokuz Mayis University, Faculty of Medicine, Department of Cardiology, Samsun, Turkey

Correspondence to: Asli Tanrivermis Sayit Ondokuz Mayis University, Faculty of Medicine, Department of Radiology, Kurupelit, 55270, Atakum, Samsun, Turkey Tel: +90 5324949082

E-mail: draslitanrivermissayit@gmail.com

Received: 30 January 2021

Accepted: 10 May 2021

\section{Relationship between acute phase reactants and prognosis in patients with or without COVID-19 pneumonia}

\author{
Asli Tanrivermis Sayit ${ }^{\circledR 1}$, Muzaffer Elmali ${ }^{(1)}$, Aydın Deveci $^{\circledR 2}$, Omer Gedikli $^{\circledR 3}$
}

\section{ABSTRACT}

In December 2019, several cases of pneumonia of unknown origin were reported in the city of Wuhan, province of Hubei, China. The pathogen was named as severe acute respiratory syndrome coronavirus 2 (SARS-CoV-2) and the disease was named coronavirus disease 2019 (COVID-19). Acute phase reactans (APRs) are critical in the early diagnosis, treatment, and for monitoring the progression of COVID-19. Seventy two patients were included in the study and infections confirmed by real-time reverse transcription polymerase chain reaction. Clinical parameters, the level of APFs and D-dimer were assessed and results were retrived from the patients' medical records. Chest computed tomography (CT) findings were described for each patient and they were divided into two groups, with or without COVID-19 pneumonia. The correlation between APRs and CT findings and the patients' prognosis were evaluated. Twenty eight $(38.8 \%)$ of the 72 patients were female and $44(61.2 \%)$ were male. The most common symptom was cough (43\%) and the most common associated chronic disease was hypertension $(12.5 \%)$. Thirty $(41.6 \%)$ patients had completely normal chest CT, while 42 (58.4\%) patients had typical findings in terms of COVID-19 pneumonia. C reactive protein (CRP), lactate dehydrogenase (LDH), erythrocyte sedimentation rate (ESR), ferritin, procalcitonin and D-Dimer levels were statistically significantly higher in patients with pneumonia than in those without pneumonia and these parameters were also statistically significantly higher in patients with severe illness. In conclusion, CRP, LDH, ESR, ferritin, and D-Dimer were associated with severe COVID-19 pneumonia. These biomarkers can be used to evaluate the prognosis to predict the clinical course of disease, allowing a proper management and treatment of the patients.

KEYWORDS: Acute phase reactans. SARS-CoV-2. COVID-19. Computed tomography. Pneumonia.

\section{INTRODUCTION}

In December 2019, several cases of pneumonia of unknown origin were reported in the city of Wuhan, province of Hubei, China ${ }^{1}$. In January 2020, this pathogen was identified by Chinese scientists as a more infectious coronavirus, similar to the ones of the severe acute respiratory syndrome coronavirus (SARS-CoV) and the Middle East respiratory syndrome coronavirus (MERS-CoV) ${ }^{2}$. In February 2020, this novel coronavirus was named as severe acute respiratory syndrome coronavirus 2 (SARS-CoV-2) by the International Committee on Taxonomy of Viruses, and the disease was named coronavirus disease 2019 (COVID-19) by the World Health Organization (WHO) ${ }^{1}$. SARS-CoV-2 has affected more than 183 countries and territories in a short time due to its high transmission, and a pandemic was declared by the WHO in March 2020. SARS-CoV-2 is transmitted from 
human to human by multiple means, namely, by droplets, aerosols, and fomites ${ }^{3}$. Although SARS-CoV-2 mostly causes mild symptoms, such as fever, cough, myalgia, and fatigue, it may trigger serious clinical complications such as pneumonia, pulmonary edema, acute respiratory distress syndrome (ARDS), multiple organ failure and septic shock ${ }^{3}$. SARS-CoV-2 enters the host cells by the binding with the angiotensin-converting enzyme 2 (ACE2) receptor ${ }^{4}$. ACE2 is present in many cell types and tissues, including the lungs, heart, blood vessels, kidneys, liver and gastrointestinal tract. It is present in epithelial cells, in some specific cell in certain tissues, creating a protective barrier ${ }^{4}$. When SARS-CoV-2 binds to ACE2, it prevents ACE2 from performing its normal function of regulating angiotensin 2 signaling. Thus, ACE2 action is inhibited, and abundant angiotensin 2 is produced, leading to tissue damage. Therefore, ACE2 contributes to tissue damage, especially in the lungs and heart in patients with COVID-195. The virus reaches the lungs after entering the nose or mouth, and it can cause respiratory problems, such as pneumonia ${ }^{2}$. The reverse transcription polymerase chain reaction (RT-PCR) test is a real-time RT-PCR (rRT-PCR) test to qualitatively detect nucleic acid from SARS-CoV-2 in the upper and the lower respiratory specimens (e.g., nasopharyngeal and oropharyngeal swabs), providing evidence for a definitive diagnosis of COVID- $19^{6}$. The shortage of kits and the false negative rate of RT-PCR results (2-29\%) cause delays in the early diagnosis and treatment of patients ${ }^{6}$. This situation led clinicians to request the chest computed tomography (CT) scans to reveal the involvement of lungs and to achieve an early treatment in patients suspected to have COVID-19, especially those with complaints such as fever, dyspnea and cough ${ }^{3}$. Typical findings, such as peripheral multifocal ground glass opacities, a disorganized paving pattern and the presence of a reverse halo have been described in the chest CT scans of patients with a definitive diagnosis of COVID-19. Therefore, chest CT plays a critical and significant role in the early diagnosis and treatment of COVID-19, as the mortality rates of COVID-19 pneumonia are high ${ }^{2,3}$.

Acute phase reactants (APRs) are inflammation biomarkers that exhibit significant changes in their serum concentrations during inflammation caused by infectious and noninfectious conditions. APRs are used for the early diagnosis, to distinguish infectious diseases from noninfectious ones and to evaluate the response to treatment ${ }^{7}$. Important APRs include the erythrocyte sedimentation rate (ESR), C-reactive protein (CRP), lactate dehydrogenase (LDH), fibrinogen, ferritin, procalcitonin, D-dimer and troponin ${ }^{7}$. The concentrations of all these positive APRs increase in the serum during inflammation.
D-Dimer is a cross-linked fibrin breakdown product and a small fragment of protein that is present in the blood after a clot breaks down during fibrinolysis.

Recent studies have shown that elevated D-dimer levels indicate a poor prognosis in patients with COVID-19,9. Early diagnosis and evaluation of the disease severity in patients infected with SARS-CoV-2 is critical for the medical management and treatment. Our aim was to evaluate the relationship between laboratory findings (APRs and D-dimer) in patients with and without COVID-19 pneumonia. In addition, we investigated the relationship between laboratory values and the prognosis of these patients.

\section{MATERIALS AND METHODS}

This study was approved by the institutional review board of the Ondokuz Mayis University Faculty of Medicine and the Ethics Committee of this hospital. The stsudy procedures were in accordance with the Declaration of Helsinki (2020/340). In addition, approval of the study was obtained from the Republic of Turkey Ministry of Health. This study did not have any funding.

\section{Study population}

This retrospective study included 72 patients ( 28 female, 44 male) who were diagnosed with COVID-19 by RT-PCR. They sought the emergency department presenting with symptoms such as fever, dry cough, weakness and underwent chest $\mathrm{CT}$ on admission to the hospital. All patients included in the study were newly diagnosed and untreated at the time of admission to the emergency department of the Ondokuz Mayis University Faculty of Medicine in Samsun, Turkey. The medical information of all patients were retrospectively retrieved from their medical records and evaluated. Age, gender, comorbidities, symptoms on admission, levels of APRs and D-dimer and chest $\mathrm{CT}$ findings were collected for each patient before the treatment. Blood samples (APRs and D-dimer) were taken on admission to the hospital for each patient. Patients with underlying diseases, such as tuberculosis, lung carcinomaor other chronic lung diseases were excluded from the study.

All patients were treated with the same treatment protocol according to the COVID-19 guidelines of the Turkish Ministry of Health (hydroxychloroquine, azithromycin, favipiravir and enoxaparin sodium) between January and June 2020.

The COVID-19 patients were divided into two groups according to the disease severity: mild or severe. Patients were considered to have mild disease if they received 
medical treatment and were isolated at home or in a hospital and they were subsequently discharged. Patients were considered to have severe disease if they received oxygen therapy and medical care during hospitalization or were admitted to the intensive care unit (ICU) with only oxygen support and/or required intubation and respiratory support. We evaluated the relationship between the levels of APRs and the prognosis of the patients.

\section{Image acquisition and analysis}

During the first admission to the hospital, chest CT (Canon, Aquilion Prime SP, Canon Medical Systems, Japan) was performed in patients suspected of having pneumonia due to COVID-19 and presenting with symptoms such as dyspnea, cough and fever. Unenhanced chest CT scans were obtained with a low dose technique $(\mathrm{mA}, \mathrm{kV}: 150$, slice thickness: $1 \mathrm{~mm}$ ) in the CT unit, which was specifically located in an isolated area of the emergency department.

The chest CT scans of each patient were independently evaluated by two experienced radiologists (A.T.S. and M.E.) in thoracic radiology. Chest CT findings such as ground glass opacification, consolidation, disorganized paving pattern, and reverse halo, which are typically described in COVID-19 pneumonia, were considered to be indicative of COVID-19 pneumonia. Patients with normal chest imaging were allocated in the group without pneumonia. All laboratory tests were collected on the same date that the chest $\mathrm{CT}$ was performed. We investigated whether there were associations between APRs and D-dimer values in patients with (group A) and without pneumonia (Group B).

\section{Statistical analysis}

The SPSS Statistics package, version 21 for Windows (IBM SPSS Inc., Armonk, NY, USA) was used to perform all statistical analyses. The normality of the variables distribution was examined by the Shapiro-Wilk test. Descriptive analyses results were expressed as the mean and standard deviations for normally distributed variables. The median (minimum-maximum values) were used for non-normally distributed variables. Categorical variables were expressed as percentages. No more than one blood sample was taken from all patients. The student t-test was used to compare normally distributed variables, and the Mann-Whitney U test was used to compare non-normally distributed variables. In the comparisons of categorical variables, the chi-square test or the Fisher's exact test were used. A value of $p<0.05$ was considered significant in all statistical analyses.

\section{RESULTS}

From the total of 72 patients (mean age: $45.08 \pm 17.1$ years), $28(38.8 \%)$ were female, and $44(61.2 \%)$ were male. The mean age of male patients was higher than that of female patients $(46.43 \pm 16.50$ years vs. $44.23 \pm 17.60$ years, $\mathrm{p}=0.59)$. The most common symptom of the patients was cough (43\%), and the second most common symptom was fever (20.8\%). Of the 72 patients, 23 (31.9\%) had a history of one or more chronic diseases or a history of cancer treatment. The most commonly reported chronic disease was hypertension (HT) $(12.5 \%)$. The demographic findings are shown in Table 1.

Table 1 - Demographic data of the 72 patients with COVID-19.

\begin{tabular}{|c|c|c|}
\hline \multicolumn{2}{|c|}{ Patients' demographic data } & \multirow{2}{*}{$\frac{\text { Number of cases }}{9(12.5 \%)}$} \\
\hline \multirow{10}{*}{$\begin{array}{l}\text { Comorbid } \\
\text { conditions }\end{array}$} & Hypertension & \\
\hline & Previous carcinoma history & $7(9.7 \%)$ \\
\hline & Diabetes mellitus & $5(6.9 \%)$ \\
\hline & Coronary artery disease & $4(5.5 \%)$ \\
\hline & COPD & $3(4.1 \%)$ \\
\hline & Hyperlipidemia & $2(2.7 \%)$ \\
\hline & Cerebrovascular disease & $2(2.7 \%)$ \\
\hline & Chronic kidney disease & $1(1.3 \%)$ \\
\hline & Other comorbidities & $2(2.7 \%)$ \\
\hline & Non reported & $37(51.4 \%)$ \\
\hline Total & & 72 \\
\hline \multirow{7}{*}{$\begin{array}{l}\text { Sign and } \\
\text { semptoms }\end{array}$} & Cough & $31(43 \%)$ \\
\hline & Fever & $15(20.8 \%)$ \\
\hline & Dyspnea & $6(8.3 \%)$ \\
\hline & Chest pain & $4(5.5 \%)$ \\
\hline & Fatigue weakness & $3(4.1 \%)$ \\
\hline & Diarrhea & $2(2.7 \%)$ \\
\hline & No symptoms & $11(15.2 \%)$ \\
\hline Total & & 72 \\
\hline \multirow{2}{*}{ Gender } & Female & $28(38.8 \%)$ \\
\hline & Male & $44(61.2 \%)$ \\
\hline Total & & 72 \\
\hline \multirow{2}{*}{ Age (years) } & Female & $46.43 \pm 16.50$ \\
\hline & Male & $44.23 \pm 17.60$ \\
\hline
\end{tabular}

COVID-19 = Coronavirus disease 2019; COPD = Chronic obstructive pulmonary disease.

During the first admission to the hospital, 30 (41.6\%) patients had completely normal chest CT scans, while $42(58.4 \%)$ patients had typical findings of COVID-19 pneumonia. The age of patients who had pneumonia was significantly higher than that of those with normal chest CT $(51.5 \pm 15.8$ years vs. $36 \pm 14.5$ years, $\mathrm{p}<0.001)$. Of the 
42 patients with pneumonia, 15 were female (35.7\%), and 27 were male $(64.3 \%)$. Signs of pneumonia infiltration were more frequently found in men. The age of female patients who had pneumonia was higher than that of male patients $(55.2 \pm 14.8$ years vs. $49.5 \pm 16.3$ years, $\mathrm{p}=0.51)$. The age of female patients who had pneumonia was significantly higher than those of female patients without pneumonia $(55.2 \pm 14.8$ years vs. $36.2 \pm 12.1$ years, $\mathrm{p}=0.001)$. In the same way, the age of the male patients who had pneumonia was significantly higher than those of male patients without pneumonia $(49.5 \pm 16.3$ years vs. $35.8 \pm 16.6$ years, $\mathrm{p}=0.01)$. The demographic findings of the patients with or without pneumonia are shown in Table 2. Among the 42 patients with pneumonia, the infiltration was bilateral in 34 patients (47.2\%) (12 females, 22 males) (Figure 1), located only on the left side in 3 patients (4.2\%) (1 female, 2 males), and in the right side in 5 patients $(6.9 \%$ ) ( 2 females, 3 males) (Figure 2). The most common chest CT findings in patients with pneumonia were bilateral, peripheral, and basal, with a predominance of ground glass opacities (GGOs) and/or consolidation.

Considering the total of 72 patients, $46(63.8 \%)$ had mild disease, and $26(36.2 \%)$ had severe disease. Of the
46 patients with mild disease, 11 were isolated at treated at home, and 35 were treated in a pandemic service. Of the 26 patients with severe disease, 18 received oxygen supplementation in addition to medication in the pandemic service, and 8 were intubated and treated in the ICU. Despite the hospitalization and treatment, three of these eight patients ( 1 female, 2 males), including a 38-year-old male patient with a history of esophageal carcinoma; a 65-year-old male patient with a history of HT; and a 63-year-old female patient with a history of HT, coronary artery disease and cerebrovascular disease, died in the ICU (4.2\%). The other 69 (95.8\%) patients were discharged from the hospital.

The laboratory findings and statistical results of patients with pneumonia in group A and without pneumonia in group B are shown in Table 3. Only the necessary APRs were assessed and no unnecessary blood tests were performed. All APR samples were taken considering the signs and symptoms of the patients. In addition, this procedure did not affect the comparison between groups.

The laboratory findings of the patients and the statistical results of those with severe and mild disease are shown in Table 4.

Table 2 - Demographic data of the 72 patients with COVID-19 divided into two groups: with (42) or without pneumonia (30).

\begin{tabular}{llccc}
\hline \multicolumn{2}{l}{ Patients' demographics } & With pneumonia & Without pneumonia & $\mathrm{p}$ \\
\hline \multirow{2}{*}{ Gender } & Female & $15(35.7 \%)$ & $13(18 \%)$ & 0.51 \\
& Male & $27(64.3 \%)$ & $17(23.6 \%)$ & \\
\hline \multirow{2}{*}{ Age } & Female & $55.2 \pm 14.8$ years & $36.2 \pm 12.1$ years & 0.001 \\
& Male & $49.5 \pm 16.3$ years & $35.8 \pm 16.6$ years & 0.01 \\
\hline
\end{tabular}
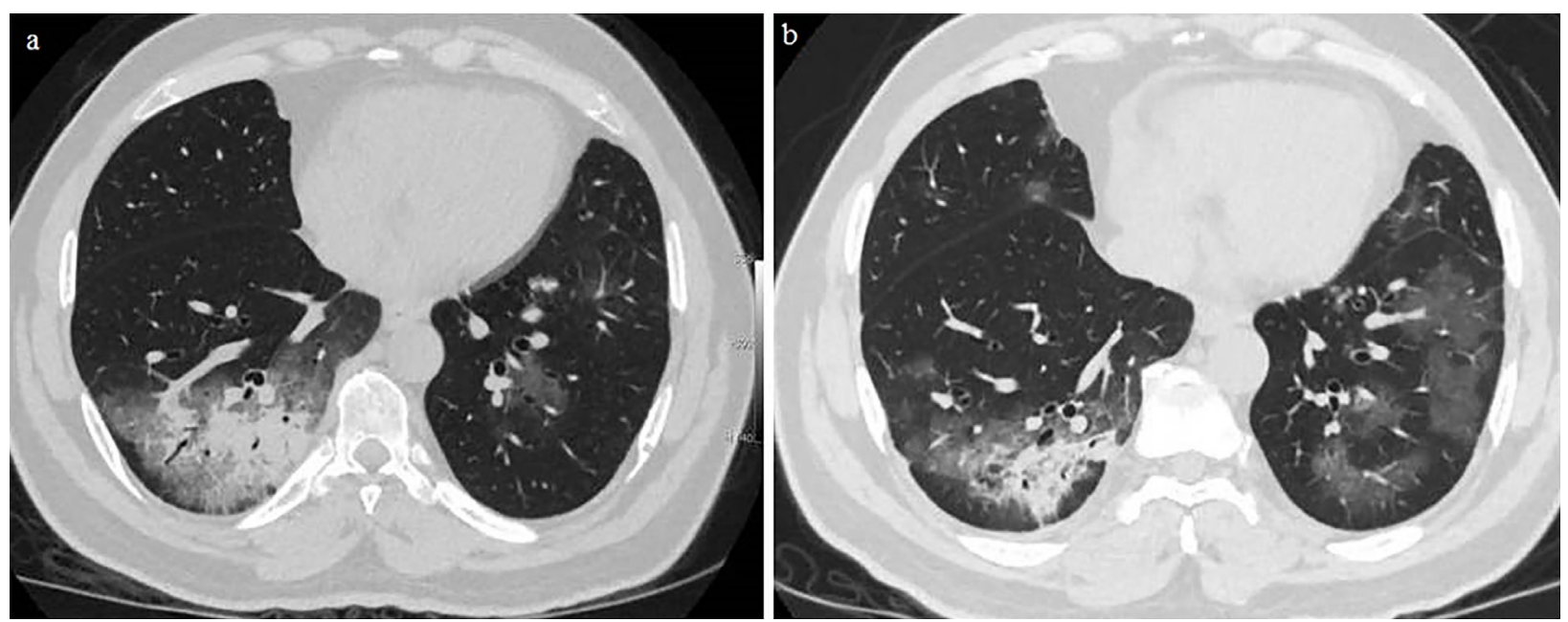

Figure 1 - A 54-year-old woman presenting with fever: (A) Her first axial unenhanced low dose chest computed tomography (CT) showed a focal rounded ground glass opacity (GGO) in the lateral basal segment of the left lower lobe. Acute phase reactan levels were abnormal except for troponin and C-reactive protein (CRP) on the first admission. Ferritin was $120 \mathrm{ng} / \mathrm{mL}$, Lactate dehydrogenase (LDH) was $198 \mathrm{U} / \mathrm{L}$, erythrocyte sedimentation rate (ESR) was $22 \mathrm{~mm} / \mathrm{h}$; (B) After 3 days, her follow-up CT scan showed progression of the GGOs as well as a ferritin of $144 \mathrm{ng} / \mathrm{mL}$, LDH of $212 \mathrm{U} / \mathrm{L}$, ESR of $28 \mathrm{~mm} / \mathrm{h}$, and CRP of $4 \mathrm{mg} / \mathrm{L}$. Her troponin was normal. 

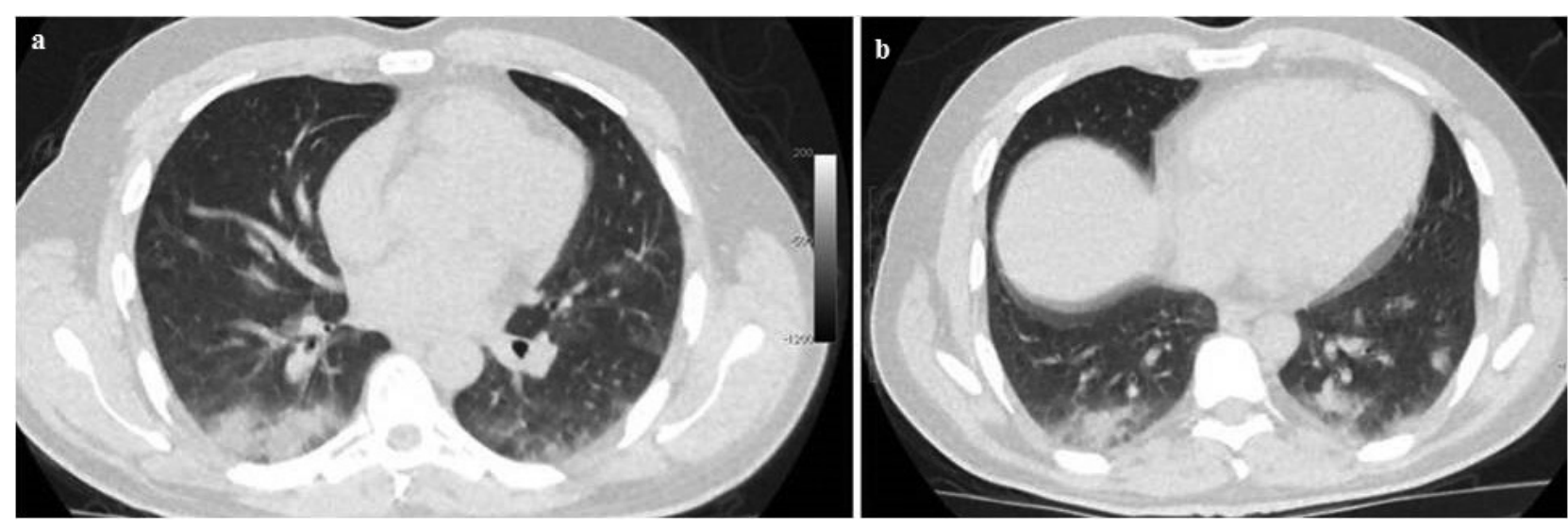

Figure 2 - A 56-year-old male patient presenting with myalgia: (A) His first axial unenhanced low dose chest CT showed GGOs with consolidation in the basal segments of the right lower lobe. Furthermore, there were multifocal and multisegmenter GGOs in the left lower lobe. Acute phase reactan levels were abnormal except for the first troponin on admission. CRP was $172 \mathrm{mg} / \mathrm{L}$, procalcitonin was 3,8 ng/mL and D-dimer was $231 \mathrm{ng} / \mathrm{mL}$; (B) After 4 days, the follow-up CT scan showed progression of the GGOs in the left lower lobe with a regression of the consolidation in the right lower lobe. Moreover, CRP was $41 \mathrm{mg} / \mathrm{L}$, procalcitonin was $0.7 \mathrm{ng} / \mathrm{mL}$, ferritin was $310 \mathrm{ng} / \mathrm{mL}$, LDH was $297 \mathrm{U} / \mathrm{L}$, D-dimer was $242 \mathrm{ng} / \mathrm{mL}$.

Table 3 - Laboratory findings (presented as mean values + or - standard deviations) of the patients with pneumonia ( $\mathrm{n}=42)$ and without COVID-19 pneumonia $(n=30)$.

\begin{tabular}{lcccc}
\hline Acute phase reactans & With pneumonia & Without pneumonia & p & Normal range \\
\hline C reactive protein $(\mathrm{mg} / \mathrm{L})$ & $69.9+$ or $-92.1(\mathrm{n}=42)$ & $12.5+$ or $-26.4(\mathrm{n}=28)$ & $<0.001$ & $0-5$ \\
LDH $(\mathrm{U} / \mathrm{L})$ & $294+$ or $-160(\mathrm{n}=39)$ & $215.1+$ or $-81.2(\mathrm{n}=26)$ & $<0.001$ & $135-214$ \\
ESR $(\mathrm{mm} / \mathrm{h})$ & $47.7+$ or $-33.1(\mathrm{n}=35)$ & $19.2+$ or $-15.6(\mathrm{n}=13)$ & 0.001 & $1-15$ \\
Fibrinogen $(\mathrm{mg} / \mathrm{dL})$ & $512.6+$ or $-222.1(\mathrm{n}=13)$ & $350+$ or $-153.1(\mathrm{n}=9)$ & 0.04 & $200-400$ \\
Ferritin $(\mathrm{ng} / \mathrm{mL})$ & $515.8+$ or $-115(\mathrm{n}=38)$ & $100.7+$ or $-74.9(\mathrm{n}=24)$ & $<0.001$ & $21-274$ \\
Procalcitonin $(\mathrm{ng} / \mathrm{mL})$ & $0.25+$ or $-0.67(\mathrm{n}=35)$ & $0.05+$ or $-0.02(\mathrm{n}=23)$ & $<0.001$ & $<0.02$ \\
D-Dimer $(\mathrm{ng} / \mathrm{mL})$ & $585+$ or $-644(\mathrm{n}=36)$ & $182+$ or $-174.9(\mathrm{n}=28)$ & $<$ M0.001 & $<250$ \\
Troponin I $(\mathrm{ng} / \mathrm{mL})$ & $0.012+$ or $-0.10(\mathrm{n}=42)$ & $0.013+$ or $-(0.10)(\mathrm{n}=30)$ & 0.59 & $<0.012$ \\
\hline
\end{tabular}

$\mathrm{LDH}=$ Lactate dehydrogenase; ESR = Erythrocyte sedimentation rate.

Table 4 - Laboratory finding of the mild cases $(n=46)$ and the severe cases $(n=26)$ of COVID-19 in this study. Note that not all the laboratory parameters were evaluated in all the patients. Laboratory results were presented as median (min-max) values.

\begin{tabular}{|c|c|c|c|}
\hline Acute phase reactans & COVID-19 classification & Median (min-max) values & $p$-value \\
\hline \multirow[t]{2}{*}{ C reactive protein $(\mathrm{mg} / \mathrm{L})^{\star}$} & Mild $(n=44)$ & $5.15(1-126)$ & $<0.001$ \\
\hline & Severe $(n=26)$ & $44(2-435)$ & \\
\hline \multirow[t]{2}{*}{$\mathrm{LDH}(\mathrm{U} / \mathrm{L})^{\star}$} & Mild $(n=42)$ & $203.5(133-662)$ & 0.014 \\
\hline & Severe $(n=23)$ & $243(144-908)$ & \\
\hline \multirow[t]{2}{*}{$\overline{\mathrm{ESR}}(\mathrm{mm} / \mathrm{h})^{\dagger}$} & Mild $(n=27)$ & $25.7+$ or -15.0 & 0.001 \\
\hline & Severe $(n=21)$ & $58.4+$ or -38.3 & \\
\hline \multirow[t]{2}{*}{ Fibrinogen $(\mathrm{mg} / \mathrm{dL})^{*}$} & Mild $(n=14)$ & $271(225-686)$ & 0.041 \\
\hline & Severe $(n=8)$ & $521(329-1,032)$ & \\
\hline \multirow[t]{2}{*}{ Ferritin $(\mathrm{ng} / \mathrm{mL})^{\star}$} & Mild $(n=41)$ & $110(7-1,157)$ & 0.001 \\
\hline & Severe $(n=21)$ & $310(40-7,256)$ & \\
\hline \multirow[t]{2}{*}{ Procalcitonin $(\mathrm{ng} / \mathrm{mL})^{*}$} & Mild $(\mathrm{n}=36)$ & $0.05(0.02-03)$ & 0.02 \\
\hline & Severe $(n=22)$ & $0.09(0.04-3.8)$ & \\
\hline \multirow[t]{2}{*}{ D-dimer $(\mathrm{ng} / \mathrm{mL})^{*}$} & Mild $(n=42)$ & $231.5(73-2,323)$ & 0.007 \\
\hline & Severe $(n=22)$ & $318(044-3,001)$ & \\
\hline \multirow[t]{2}{*}{ Troponin I (ng/mL)* } & Mild $(\mathrm{n}=46)$ & $0.10(0.1-0.9)$ & 0.74 \\
\hline & Severe $(n=26)$ & $0.09(0.04-3.8)$ & \\
\hline
\end{tabular}

†Mean \pm standard deviation; *Median (range); LDH = Lactate dehydrogenase; ESR = Erythrocyte sedimentation rate. 


\section{DISCUSSION}

SARS-CoV-2 is a novel coronavirus and generally causes mild respiratory disease ${ }^{1}$. However, it can cause severe pneumonia, which may progress to ARDS, shock, multiorgan failure and death. The mortality rates of COVID-19 pneumonia have been reported as $4.3 \%^{10}, 11 \%{ }^{3}$ and $14.6 \%{ }^{2}$ in recent publications. In addition, the severity of illness and mortality are increased by comorbidities, such as cerebrovascular disease, cardiovascular disease, HT and diabetes mellitus ${ }^{3}$. In our study, three of the 72 patients died, and the mortality rate was $4.1 \%$, which is similar to the ones in the literature.

RT-PCR is the recommended diagnostic test to detect SARS-CoV-2 RNA from the upper respiratory tract ${ }^{6}$. However, RT-PCR may generate false-negative results due to insufficient swab samples, which are collected from the oropharynx or nasopharynx ${ }^{11}$. False negative RT-PCR results may delay the diagnosis and the early treatment of patients, especially those with COVID-19 pneumonia, increasing the risk of community transmission ${ }^{11}$. Therefore, clinicians have begun to request chest $\mathrm{CT}$ scans to evaluate the lungs, especially in patients with suspected pneumonia, for the early diagnosis and treatment of the patients ${ }^{11}$.

A bilateral distribution of GGOs with or without consolidation in the posterior and peripheral lung is the most common chest CT finding in patients with COVID-19 pneumonia $^{12}$. Pleural effusion, pericardial effusion, cavitation and mediastinal and/or hilar lymphadenopathy are rarely observed in COVID-19 $19^{12}$. In our study, a bilateral multifocal peripheral and basal distribution of GGOs predominated as they were detected in 34 of 42 patients with COVID-19 pneumonia. Pneumonia infiltration was detected in the left lung of three patients and the right lung of five patients.

APRs are critical for the early diagnosis, treatment, and for monitoring the progression of COVID-19. The acute-phase response to a tissue injury and inflammation is accompanied by a dramatic increase in the hepatic synthesis of plasma proteins known as APRs. The most important APRs include serum CRP, the ESR, LDH, fibrinogen, ferritin, procalcitonin and troponin ${ }^{7}$.

CRP is one of the best indicators of the acute phase response to inflammation. This serum protein is synthesized by hepatocytes and is classified as an acute-phase protein based on its increased serum concentration during inflammation and infection ${ }^{13}$. Normal levels of the CRP are inferior to $5 \mathrm{mg} / \mathrm{L}^{3}$. Tan et al. ${ }^{13}$ reported that CRP levels are positively-associated with $\mathrm{CT}$ severity scores in patients with COVID-19. They found that the area under the curve for CRP on the first visit is able to predict severe COVID-19 and was 0.87 (95\% CI $0.10-1.00)$ considering a a cut-off of 20.42 $\mathrm{mg} / \mathrm{L}$, with high sensitivity and specificity ${ }^{13}$. In addition, Zhang et al. ${ }^{14}$ revealed that there were no patients with severe clinical disease and lower CRP $(<20 \mathrm{mg} / \mathrm{L})$ levels, whereas $84 \%$ of patients who had severe clinical disease, had higher CRP levels ( $>150 \mathrm{mg} / \mathrm{L}$ ). They reported that a higher CRP level was strongly associated with severe COVID-19 pneumonia ${ }^{14}$. In our study, all CRP levels were higher than 5 $\mathrm{mg} / \mathrm{L}$ in 41 patients (80\%) and 12 of these patients CRP levels were higher than $100 \mathrm{mg} / \mathrm{L}$. CRP was significantly higher in patients with pneumonia than in those without pneumonia. In addition, the CRP value was significantly higher in patients with severe disease than in patients with mild disease. Therefore, our study supports the strong relationship between high CRP values and severe COVID-19.

The ESR is the sedimentation rate of red blood cells under certain conditions. Although the increase in the ESR in patients with COVID-19 cannot be fully explained, it is thought that an increase in the ESR occurs through changes in the erythrocyte forms and plasma characteristics ${ }^{13}$. Normal levels of the ESR are $<15 \mathrm{~mm} / \mathrm{h}^{3}$. Tan et al. ${ }^{13}$ reported that ESR levels were significantly elevated in the early stage, in patients with severe COVID-19, while no significant difference in the chest CT scores could be identified between patients with severe and mild disease. In our study, ESR levels were higher than $15 \mathrm{mg} / \mathrm{L}$ in 38 patients $(79.1 \%)$ and three of these patients had ESR levels higher than $100 \mathrm{mg} / \mathrm{L}$. ESR was significantly higher in patients with pneumonia than in those without pneumonia. In addition, the ESR value was significantly higher in patients with severe clinical disease than in those with mild disease.

LDH is found in all human cells, especially in myocardial and liver cells ${ }^{15}$. LDH secretion is triggered by necrosis of the cell membrane ${ }^{15}$. Studies in the literature identified that LDH could be a powerful predictive factor for the early recognition of lung injury ${ }^{16}$. The normal range of LDH is 120-250 U/L ${ }^{3}$. Zhang et al. ${ }^{14}$ revealed that all patients whose LDH levels were higher than $720 \mathrm{U} / \mathrm{L}$ had severe disease, and a higher LDH activity was strongly correlated with severe COVID-19 pneumonia. In our study, LDH levels were higher than $250 \mathrm{U} / \mathrm{L}$ in 21 patients (32.3\%). LDH value was significantly higher in patients with pneumonia than in those without pneumonia. In addition, the LDH value was significantly higher in patients with severe disease than in those with mild disease.

Ferritin is an iron storage protein and an inflammatory biomarker ${ }^{17}$. Serum ferritin is a marker of acute and chronic inflammation and is nonspecifically elevated in a wide range of inflammatory conditions ${ }^{17}$. Normal ferritin levels range from 21 to $274 \mathrm{ng} / \mathrm{mL}^{3}$. Although the exact mechanisms of hyperferritinemia and disease severity in patients with 
COVID-19 remain unclear, it is thought that the stimulation of proinflammatory cytokines by SARS-CoV 2 triggers ferritin synthesis ${ }^{17}$. In addition, cellular damage secondary to inflammation can promote the leakage of intracellular ferritin, thus increasing serum ferritin levels ${ }^{17}$. Lin et al. ${ }^{17}$ reported that higher serum ferritin predicted an increased risk of disease severity in patients with COVID-19. In this study, ferritin levels were higher than $274 \mathrm{ng} / \mathrm{mL}$ in 19 patients (30\%) and two of these patients had ferritin levels higher than $1,000 \mathrm{ng} / \mathrm{mL}$. Moreover, ferritin levels were significantly higher in patients with pneumonia than in those without pneumonia. In addition, ferritin levels were significantly higher in patients with severe disease than in those with mild disease.

Procalcitonin is a 116-amino acid precursor of the hormone calcitonin ${ }^{18}$. There is increasing evidence on the usefulness of procalcitonin as a biomarker in lower respiratory tract infections ${ }^{7}$. It has been reported that procalcitonin is remarkably useful for the early diagnosis of bacterial pneumonia, guiding antibiotic therapy and predicting the patients who have a higher risk of developing complications ${ }^{7}$. Normal levels of procalcitonin are $<0.5 \mathrm{ng} / \mathrm{mL}$. Procalcitonin rarely exceeds $0.5 \mathrm{ng} / \mathrm{mL}$ in viral infections ${ }^{1}$. Recent studies have demonstrated that procalcitonin levels positively correlate with the severity of COVID-192,14,19. In addition, Lippi et al. ${ }^{20}$ reported a metaanalysis and showed that increased procalcitonin levels are related to an approximately 5-fold higher risk of severe COVID-19. Hu et al. ${ }^{18}$ revealed that the procalcitonin value was 4 times higher in patients with severe disease than in those with moderate disease, and 8 times higher in patients with critical disease than in patients with moderate disease. In addition, they reported that a progressive increase in the procalcitonin level is associated with poorer prognosis. Here, procalcitonin levels were higher than $0.05 \mathrm{ng} / \mathrm{mL}$ in 34 patients $(58.6 \%)$ and 11 of these patients had procalcitonin levels higher than $0.10 \mathrm{ng} / \mathrm{mL}$. Furthermore, procalcitonin levels were significantly higher in patients with pneumonia than in those without pneumonia. In addition, procalcitonin levels were significantly higher in patients with severe disease than in patients with mild disease.

D-dimers are protein products of the cross-linked fibrin break down that are present in the blood of most healthy individuals in only insignificant amounts ${ }^{21}$. D-Dimer and fibrinogen are sensitive indicators of coagulation dysfunctions. Increased D-dimer levels indicate hypercoagulability and secondary fibrinolysis ${ }^{21}$. High levels of D-dimer have been reported to determine the severity of pneumonia and the early diagnosis of sepsis in these patients ${ }^{1}$. Long et al. ${ }^{21}$ reported that coagulation disorders occur in the early stage of COVID-19 and that an increase in
D-dimer and fibrinogen levels were significantly correlated with the parenchymal progression to pneumonia in the chest CT. They also reported that fibrinogen and D-dimer levels were significantly elevated in seriously ill COVID-19 patients $^{21}$. In this study, D-dimer levels were significantly higher in patients with pneumonia than in those without pneumonia. D-dimer levels were higher than $250 \mathrm{ng} / \mathrm{mL}$ in 36 patients (56\%) and four of these patients had D-Dimer levels higher than $1,000 \mathrm{ng} / \mathrm{mL}$. In addition, D-dimer levels were significantly higher in patients with severe disease than in those with mild disease. Moreover, pulmonary embolism was suspected in a patient with a high D-dimer level $(676 \mathrm{ng} / \mathrm{mL})$ who was treated in the ICU due to the development of dyspnea. Pulmonary CT angiography was performed, and the findings showed no pulmonary emboli but did show the presence of pneumonia infiltration.

It has been reported that increased troponin I levels in COVID-19 patients are associated with an adverse prognosis and mortality ${ }^{22}$. Normal levels of the cardiac troponin are less than $0.012 \mathrm{ng} / \mathrm{mL}^{23}$. Elevated troponin I levels can be explained by several mechanisms, including viral myocarditis, cytokine-induced myocardial damage, microangiopathyand coronary artery disease, although the related mechanisms have not been proven ${ }^{22}$. It is thought that the renin-angiotensin-aldosterone system is disrupted in patients with COVID-19, and decreased ACE2 is associated with cardiovascular injuries ${ }^{22}$. In this study, troponin I levels were higher than $0.012 \mathrm{ng} / \mathrm{mL}$ in five patients, but there were no statistically significant differences between troponin values in patients with and without pneumonia. in our study. Furthermore, there was no statistically significant difference in patients with severe disease than in patients with mild disease.

The limitations of our study include the low number of patients. In addition, laboratory tests were not performed for every patient. They were performed only in cases in which they were deemed necessary. This situation reduced the sample size.

\section{CONCLUSION}

In conclusion, CRP, LDH, ESR, ferritin, and D-dimer were associated with severe COVID-19 pneumonia. These biomarkers can be used to evaluate the prognosis, to predict the clinical course, and to help the management and the treatment of these patients.

\section{CONFLICT OF INTERESTS}

The authors declare that they have no confict of interest related to the publication of this article. 


\section{ETHICAL APPROVAL}

All procedures performed in studies involving human participants were in accordance with the ethical standards of the institutional and/or national research committee and with the 1964 Helsinki Declaration and its later amendments or comparable ethical standards.

\section{FUNDING}

The authors declared that this study has received no financial support.

\section{REFERENCES}

1. Yormaz B, Ergun D,Tulek B, Ergun R, Korez KM, Suerdem M, et al. The evaluation of prognostic value of acute phase reactants in the COVID-19. Bratisl Lek Listy. 2020;121:628-33.

2. Huang C, Wang Y, Li X, Ren L, Zhao J, Hu Y, et al. Clinical features of patients infected with 2019 novel coronavirus in Wuhan, China. Lancet. 2020;395:497-506.

3. Chen N, Zhou M, Dong X, Qu J, Gong F, Han Y, et al. Epidemiological and clinical characteristics of 99 cases of 2019 novel coronavirus pneumonia in Wuhan, China: a descriptive study. Lancet. 2020;395:507-13.

4. Hoffmann M, Kleine-Weber H, Schroeder S, Krüger N, Herrler $\mathrm{T}$, Erichsen S, et al. SARS-CoV-2 cell entry depends on ACE2 and TMPRSS 2 and is blocked by a clinically proven protease inhibitor. Cell. 2020; 181:271-80.e8.

5. Ni W, Yang X, Yang D, Bao J, Li R, Xiao Y, et al. Role of angiotensin-converting enzyme 2 (ACE2) in COVID-19. Crit Care. 2020;24:422.

6. Arevalo-Rodriguez I, Buitrago-Garcia D, Simancas-Racines D, Zambrano-Achig P, Del Campo R, Ciapponi A, et al. Falsenegative results of initial RT-PCR assays for COVID-19: a systematic review. PLoS One. 2020;15:e242958.

7. Markanday A. Acute phase reactants in infections: evidence-based review and a guide for clinicians. Open Forum Infect Dis. 2015;2:ofv098.

8. Guan WJ, Ni ZY, Hu Y, Liang WH, Ou CQ, He JX, et al. Clinical characteristics of 2019 novel coronavirus infection in China. N Engl J Med. 2020;382:1708-20.

9. Tang N, Li D, Wang X, Sun Z. Abnormal coagulation parameters are associated with poor prognosis in patients with novel coronavirus pneumonia. J Thromb Haemost. 2020;18:844-7.

10. Wang D, Hu B, Hu C, Zhu F, Liu X, Zhang J, et al. Clinical characteristics of 138 hospitalized patients with 2019 novel coronavirus-infected pneumonia in Wuhan, China. JAMA. 2020;323:1061-9.
11. Li Y, Yao L, Li J, Chen L, Song Y, Cai Z, et al. Stability issues of RT-PCR testing of SARS-CoV-2 for hospitalized patients clinically diagnosed with COVID-19. J Med Virol. 2020;92:903-8.

12. Xu X, Yu C, Qu J, Zhang L, Jiang S, Huang D, et al. Imaging and clinical features of patients with 2019 novel coronavirus SARS-CoV-2. Eur J Nucl Med Mol Imaging. 2020;47:1275-80.

13. Tan C, Huang Y, Shi F, Tan K, Ma Q, Chen Y, et al. C-reactive protein correlates with computed tomographic findings and predicts severe COVID-19 early. J Med Virol. 2020;92:856-62.

14. Zhang JJ, Dong X, Cao YY, Yuan YD, Yang YB, Yan YQ, et al. Clinical characteristics of 140 patients infected with SARSCoV-2 in Wuhan, China. Allergy. 2020;75:1730-41.

15. Henry BM, Aggarwal G, Wong J, Benoit S, Vikse J, Plebani M, et al. Lactate dehydrogenase levels predict coronavirus disease 2019 (COVID-19) severity and mortality: a pooled analysis. Am J Emerg Med. 2020;38:1722-6.

16. Lee IK, Liu JW, Wang L, Yang KD, Li CC, Eng HL. 2009 pandemic influenza A (H1N1): clinical and laboratory characteristics in pediatric and adult patients and in patients with pulmonary involvement. Influenza Other Respir Viruses. 2012;6:e152-61.

17. Lin Z, Long F, Yang Y, Chen X, Xu L, Yang M. Serum ferritin as an independent risk factor for severity in COVID-19 patients. J Infect. 2020;81:647-79.

18. Hu R, Han C, Pei S, Yin M, Chen X. Procalcitonin levels in COVID-19 patients. Int J Antimicrob Agents. 2020;56:106051.

19. Lu R, Zhao X, Li J, Niu P, Yang B, Wu H, et al. Genomic characterisation and epidemiology of 2019 novel coronavirus: implications for virus origins and receptor binding. Lancet. 2020;395:565-74.

20. Lippi G, Plebani M. Procalcitonin in patients with severe coronavirus disease 2019 (COVID-19): a meta-analysis. Clin Chim Acta. 2020;505:190-1.

21. Long H, Nie L, Xiang X, Li H, Zhang X, Fu X, et al. D-dimer and prothrombin time are the significant indicators of severe COVID-19 and poor prognosis. Biomed Res Int. 2020;2020:6159720.

22. Tersalvi G, Vicenzi M, Calabretta D, Biasco L, Perazzini G, Winterton D. Elevated Troponin in patients with Coronavirus disease 2019: possible mechanisms. J Cardiac Failure. 2020;26:470-5.

23. Al Abbasi B, Torres P, Ramos-Tuarez F, Dewaswala N, Abdallah A, Chen K, et al. Cardiac troponin-I and COVID-19: a prognostic tool for in-hospital mortality. Cardiol Res. 2020;11:398-404. 